\title{
Creatinine-based formulae for the estimation of glomerular filtration rate in heart transplant recipients
}

Pierre Delanaye $^{\mathrm{a}}$, Eric Nellessen $^{\mathrm{b}}$, Stéphanie Grosch $^{\mathrm{a}}$, Gisèle Depas $^{\mathrm{c}}$, Etienne Cavalier $^{\mathrm{d}}$, Jean-Olivier Defraigne ${ }^{\mathrm{e}}$, Jean-Paul Chapelle ${ }^{\mathrm{d}}$, Jean-Marie Krzesinski ${ }^{\mathrm{a}}$ and Patrizzio Lancellotti ${ }^{\mathrm{b}}$

${ }^{a}$ Department of Nephrology, ${ }^{b}$ Department of Cardiology, ${ }^{c}$ Department of Nuclear Medicine, ${ }^{d}$ Department of Clinical Chemistry and ${ }^{e}$ Department of Cardiovascular Surgery, University of Liège, CHU, Sart Tilman, Liège, Belgium

\begin{abstract}
Chronic renal failure (CRF) is a common complication in heart transplant patients. Serum creatinine has clear limitations for the detection and estimation of glomerular filtration rate (GFR). Various creatininebased formulae are classically used for GFR estimation, but little scientific evidence exists for such use in a heart transplant population. GFR was measured using the plasmatic clearance of the glomerular tracer ${ }^{51} \mathrm{Cr}$-EDTA in 27 heart transplant patients with two measures for 22 of the patients. Forty-nine measures were thus available for analysis. The precision and accuracy (Bland and Altman analysis) of the Cockcroft, simplified Modified Diet in Renal Diseases (MDRD) and new Mayo Clinic formulae were compared. The mean GFR of the population was $39 \pm 15 \mathrm{~mL} / \mathrm{min} / 1.73 \mathrm{~m}^{2}$. All formulae were well correlated with the GFR. With the Bland and Altman analysis, the accuracy of the MDRD formula appeared higher than that of the Cockcroft or the Mayo Clinic formulae (bias of $+12 \mathrm{~mL} / \mathrm{min} / 1.73 \mathrm{~m}^{2}$, vs. $+19.9 \mathrm{~mL} / \mathrm{min} / 1.73 \mathrm{~m}^{2}$, and $+22.1 \mathrm{~mL} / \mathrm{min} / 1.73 \mathrm{~m}^{2}$, respectively). The difference between the estimated and measured GFR was higher than $20 \mathrm{~mL} / \mathrm{min} / 1.73 \mathrm{~m}^{2}$ in $51 \%$ and $55 \%$ cases when using the Cockcroft and the Mayo Clinic formulae respectively, whereas the difference was only noted in $14 \%$ cases when the MDRD was used. Among creatinine-based formulae, the MDRD appears the most precise and accurate for estimating the GFR in heart transplant patients. However, when the GFR must be measured with high accuracy, we recommend the use of a reference method like inulin or ${ }^{51} \mathrm{Cr}$-EDTA plasma clearance techniques.
\end{abstract}

Keywords: heart transplantation ; MDRD ; Cockcroft ; glomerular filtration rate

Chronic renal failure (CRF) is a common complication in heart transplant patients (1-4). Although the aetiology of chronic kidney failure is multifactorial, the use of calcineurin-inhibitors has a major impact on the glomerular filtration rate (GFR) (4). The physiopathology of such nephrotoxicity is complex and still debated (5-7). Endstage renal failure (ESRF) prevalence in heart transplant patients varies from $3 \%$ to $10 \%(1,2,4,5,8-11)$. Discrepancies between studies are, at least in part, explained by different follow-up periods (the longer the follow-up period, the higher the ESRF prevalence) (9-11). Regarding CRF prevalence, study comparison is also difficult because of large discrepancies in CRF definitions (GFR under 30 or $60 \mathrm{~mL} / \mathrm{min} / 1.73 \mathrm{~m}^{2}$ ) and, even more, in methods used for GFR determination. Numerous authors use only serum creatinine to estimate GFR ( 9 , 12-15). However, this GFR marker has clear limitations because of serum concentration variation according to muscle mass and tubular secretion $(4,16-18)$. Creatinine clearance determination is especially limited by urine collection errors $(19,20)$. Reference methods for GFR measurements (inulin, iohexol, iothalamate, ${ }^{51} \mathrm{Cr}$-EDTA, etc.) are more expensive and need special infrastructures. Only few authors have used such precise methods to study GFR in heart transplant patients $(2,3,18,21)$. In clinical practice and in numerous studies, GFR has thus been estimated with creatinine-based formulae $(5,8,11,22,23)$. The ones used most frequently have been the Cockcroft and the simplified (or abbreviated) MDRD formulae $(20,24,25)$. Recently, Rule et al. from the Mayo Clinic published another interesting creatinine-based formula (26). However, all these formulae are open to criticism and have not yet been validated enough in the specific population of heart transplant recipients. The goal of the present study is to compare the accuracy and precision of the Cockcroft, MDRD and Mayo Clinic formulae for the estimation of GFR in heart transplant patients.

\section{Patients and methods}

Twenty-seven patients have been included in the study. They were regularly followed up in our institution and considered as clinically stable. All the patients have been transplanted in our University except two who have been transplanted in another Belgian University centre. The exclusion criteria were: age under $15 \mathrm{yr}$ and body mass index over $35 \mathrm{~kg} / \mathrm{m}^{2}$ because accuracy of creatinine-based formulae are known to be particularly low in paediatric and obese populations (27-31). The reference method for GFR measurement was based on plasma clearance, after a single injection bolus, of a glomerular tracer, ${ }^{51} \mathrm{Cr}$-EDTA (two samples method and slopeintercept method) as described by Chantier et al. (32). The theoretical reproducibility of the GFR measured by plasma clearance of ${ }^{51} \mathrm{Cr}$-EDTA is as low as $4 \%$ for patients with GFR over $30 \mathrm{~mL} / \mathrm{min} / 1.73 \mathrm{~m}^{2}$ and $11 \%$ for GFR below $30 \mathrm{~mL} / \mathrm{min} / 1.73 \mathrm{~m}^{2}$. Of course, this theoretical variation includes the biological variation of the GFR 
(33). In our institution, the reproducibility of the isotopic measurement is fairly similar. All the measurements are performed in fasting condition, from 8:00 to 12:00 in the morning and by the same experienced nurses. Total irradiation with this technique is very low $(0.011 \mathrm{mSv})$ when doses are adapted to weight. Results were corrected by body surface area (BSA) using the classical Du Bois and Du Bois formula (34). Serum creatinine was measured with the kinetic rate-blanked compensated creatinine Jaffé method on Modular (Roche Diagnostics, Mannheim, Germany) (35). Creatinine-based formulae are shown in Table 1. The Cockcroft formula gives a result not corrected for BSA ( $\mathrm{mL} / \mathrm{min})(24)$, although the two more recent equations give results already corrected for BSA $\left(\mathrm{mL} / \mathrm{min} / 1.73 \mathrm{~m}^{2}\right)(26,36)$. However, indexing (or not) these results with BSA has little influence on GFR results in non-obese populations such as ours (37). A second GFR isotopic measurement was obtained at least 10 months after the first one (mean time between the two measurements: $14 \pm 3$ months) in 22 patients. Forty-nine examples of GFR data are thus available for statistical analysis. Among the five patients with only one GFR measurement, one death (resistant acute rejection) and one patient who developed ESRF were noted.

Table 1. Creatinine-based formulae

Equation 1 : Cockcroft

$\mathrm{GFR}=\frac{(140-\text { age }) \times \text { weight }(\mathrm{kg})}{7.2 \times \mathrm{SCr}(\mathrm{mg} / \mathrm{dL})} \times 0.85$ (if woman)

Equation 2: simplified MDRD

$\mathrm{GFR}=186 \times \mathrm{SCr}^{-1.154} \times \mathrm{age}^{-0.203} \times 0.742$ (if woman) $\times 1.21$ (if black)

Equation 3: Mayo Clinic

GFR $=\exp \left(1.911+\frac{5.249}{\mathrm{SCr}}-\frac{2.114}{\mathrm{SCC} r^{2}}-0.00686 \times\right.$ age -0.205 (if woman)

If $\mathrm{SCr}<0.8 \mathrm{mg} / \mathrm{dL}$, use 0.8 for $\mathrm{SCr}$

\section{Statistical analysis}

Data have been expressed as mean $\pm 1 \mathrm{SD}$. The correlation (Pearson's analysis) between the estimated GFR (by the three different formulae) and the measured GFR, together with Bland and Altman analysis (38), was performed using MedCalc ${ }^{\circledR}$ (MedCalc Software, Mariakerke, Belgium) and EXCEL ${ }^{\circledR} 97$ for Windows

(Microsoft Co., Seattle, WA, USA). The bias, a measure of systematic error, has been defined as the mean of the differences between the predicted and measured GFR. Ninety-five per cent of the subjects were located between the lines of agreement (mean of the difference $\pm 1.96 \times \mathrm{SD}$ ). The narrower the limits of agreement are, the better the studied formula is to estimate the real GFR. The limits of agreement, which are dependent on SD between the mean differences between the measured and estimated GFR reflect the precision of the estimation. Formulae accuracy has also been determined by the percentage of the estimated GFR within $30 \%$ measured GFR.

\section{Results}

At least one GFR measurement was performed in 27 white heart transplant patients (five women and 22 men). The mean age was $57 \pm 12 \mathrm{yr}$, and the mean body mass index $25 \pm 3 \mathrm{~kg} / \mathrm{m}^{2}$. The mean follow-up time was $45 \pm$ 42 months (range from 2 to 180 months). At the first GFR determination, all patients were taking calcineurininhibitors (only one received tacrolimus, but all the others were treated by cyclosporin with a mean plasma level of $149 \pm 39 \mathrm{ng} / \mathrm{mL}, 16(59 \%)$ by corticoids, $14(52 \%)$ by mycophenolate mofetil and seven (26\%) by azathioprine).

At the first GFR measurement, six patients had a follow-up time of $<12$ months (mean $5 \pm 3$ months) and 21 a follow-up period of longer than 12 months ( $57 \pm 40$ months). The mean GFR was statistically higher in patients with the shortest follow-up period $\left(50 \pm 15 \mathrm{~mL} / \mathrm{min} / 1.73 \mathrm{~m}^{2}\right.$ vs. $\left.36 \pm 14 \mathrm{~mL} / \mathrm{min} / 1.73 \mathrm{~m}^{2}\right)$. For the whole population, $24(89 \%)$ had a GFR lower than $60 \mathrm{~mL} / \mathrm{min} / 1.73 \mathrm{~m}^{2}$ and 11 of them $(41 \%)$ even had a GFR between 15 and $30 \mathrm{~mL} / \mathrm{min} / 1.73 \mathrm{~m}^{2}$.

After this first determination, the GFR was measured again at least 10 months later in 22 patients. The mean GFR 10 months later remained stable in those 22 patients: $37 \pm 14 \mathrm{~mL} / \mathrm{min} / 1.73 \mathrm{~m}^{2}$ vs. $38 \pm 16 \mathrm{~mL} / \mathrm{min} / 1.73$ $\mathrm{m}^{2}$. Moreover, the mean GFR of the first 27 was not statistically different from that of the 22 patients after 10 months $\left(40 \pm 16 \mathrm{~mL} / \mathrm{min} / 1.73 \mathrm{~m}^{2}\right.$ vs. $\left.37 \pm 14 \mathrm{~mL} / \mathrm{min} / 1.73 \mathrm{~m}^{2}\right)$.

All isotopic GFR measurements (49 data) were pooled and their mean value was $39 \pm 15 \mathrm{~mL} / \mathrm{min} / 1.73 \mathrm{~m}^{2}$. Important statistical results are resumed in Table 2 . The mean serum creatinine value for all 49 examples of the data was $1.55 \pm 0.50 \mathrm{mg} / \mathrm{dL}$. Although the GFR was lower than $60 \mathrm{~mL} / \mathrm{min} / 1.73 \mathrm{~m}^{2}$ in 44 cases, the serum 
creatinine was still lower than $1.5 \mathrm{mg} / \mathrm{dL}$ in 22 cases $(50 \%)$.

The correlations between the estimated GFR using the three different formulae and the measured GFR using the isotopic method are shown in Fig. 1. Highly significant correlations were noted between the measured GFR and either the Cock-croft $(r=0.7104 \mathrm{p}<0.0001)$, MDRD $(r=0.8328 \mathrm{p}<0.0001)$ or the Mayo Clinic formula $(r=$ $0.8175 \mathrm{p}<0.0001)$. No statistical difference between correlation coefficients was found.

The Bland and Altman analyses are shown in Fig. 2. As compared with the reference method, the Cockcroft, MDRD and Mayo Clinic formulae bias were: $+19.9^{2},+12$ and $+22.2 \mathrm{~mL} / \mathrm{min} / 1.73 \mathrm{~m}^{2}$ respectively. The limits of agreement were: -7.1 to $46.9,-4.7$ to 28.7 and -4.9 to $49.2 \mathrm{~mL} / \mathrm{min} / 1.73 \mathrm{~m}^{2}$ respectively. The bias, SD and limits of agreement were significantly better for the MDRD formula compared with the Cockcroft and Mayo Clinic formulae $(\mathrm{p}<0.001)$. However, there was no statistical difference between the Cockcroft and Mayo Clinic formulae.

The difference between the GFR estimated by the MDRD formula and the measured isotopic GFR was $>20$ $\mathrm{mL} / \mathrm{min} / 1.73 \mathrm{~m}^{2}$ in $14 \%$ (seven over 49 ) population, whereas this percentage reached $51 \%(25$ over 49$)$ and $55 \%$ (27 over 49) when using the Cockcroft or the Mayo Clinic formulae for estimating the GFR. These results were thus once again in favour of the MDRD formula $(\mathrm{p}<0.0001)$.

If a relative difference was used, the GFR estimated with the MDRD formula was found within 30\% measured GFR in $43 \%$ cases, whereas the percentages were 23 and 29 for the GFR estimated by the Cockcroft or Mayo Clinic formulae respectively. However, the difference between the three formulae in this respect did not reach statistical significance.

Sixteen patients had a GFR below $30 \mathrm{~mL} / \mathrm{min} / 1.73 \mathrm{~m}^{2}$ and 28 between 30 and $60 \mathrm{~mL} / \mathrm{min} / 1.73 \mathrm{~m}^{2}$. The bias and the limits of agreement in both populations were better for the MDRD formula than for the Cockcroft or the Mayo clinic formulae (data not shown). The superiority of the MDRD formula did not reached statistical significance in the population with GFR below $30 \mathrm{~mL} / \mathrm{min} / 1.73 \mathrm{~m}^{2}$ but the number of patients included in this group was however limited.

Table 2. Statistical data from the different glomerular filtration rate (GFR) estimates. Bias is the mean difference between estimated and measured GFR. $r$ is the correlation coefficient. $r^{2}$ is the square of the correlation coefficient as a value of the variability of the predicted GFR accounts for the variability of measured $\underline{G F R}$

\begin{tabular}{lllllllll}
\hline & $\begin{array}{l}\text { Mean GFR } \\
\left(\mathrm{mL} / \mathrm{min} / 1.73 \mathrm{~m}^{2}\right)\end{array}$ & $\begin{array}{l}\text { Range } \\
\left(\mathrm{mL} / \mathrm{min} / 1.73 \mathrm{~m}^{2}\right)\end{array}$ & Bias & $r$ & $\mathrm{r}^{2}$ & SD & Limits of agreement \\
${ }^{51}$ Cr-EDTA & 39 & $8-72$ & & & & & & \\
MDRD & 51 & $17-80$ & $12^{\mathrm{b}}$ & 0.71 & 0.69 & $8.5^{\mathrm{b}}$ & -4.7 to $28.7^{\mathrm{b}}$ \\
Cockcroft $^{\mathrm{a}}$ & 59 & $19-95$ & +19.9 & 0.83 & 0.5 & 13.8 & -7.1 to 46.9 \\
Mayo Clinic & 61 & $108-15$ & +22.2 & 0.82 & 0.69 & 13.8 & -4.9 to 49.2 \\
\hline
\end{tabular}

$\mathrm{SD}$ is standard deviation, which expresses the precision of the estimates. Limits of agreement is bias $\pm 1.96 \times \mathrm{SD}$.

${ }^{a}$ Cockcroft is not indexed by BSA ( $\left.\mathrm{mL} / \mathrm{min}\right)$.

${ }^{\mathrm{b}}$ Significantly different from Cockcroft and Mayo Clinic formulae $(\mathrm{p}<0.05)$.

\section{Discussion}

Given the high prevalence of CRF in heart transplant recipients, the measurement or estimation of GFR is of great importance in this population (2-4).

GFR is usually estimated by using creatinine-based formulae (20). In our heart transplant recipients' population, it has been shown that the MDRD formula is more precise and accurate than the Cockcroft or Mayo Clinic formulae.

It is well known that serum creatinine is a poor marker of GFR in the general population $(17,20)$. This marker may be even less accurate in heart transplant recipients because this population, as others suffering from chronic disease, has a reduced muscular mass. Moreover, chronic therapy by corticoids may still aggravate this phenomenon $(16,18,30,39,40)$. Our data confirms this assumption. Fifty per cent of our patients with serum creatinine below $1.5 \mathrm{mg} / \mathrm{dL}$ had in fact a GFR of $<60 \mathrm{~mL} / \mathrm{min} / 1.73 \mathrm{~m}^{2}$. 
Fig. 1. Correlations between measured GFR (by ${ }^{51} \mathrm{Cr}$-EDTA plasmatic clearance) and estimated GFR (MDRD, Mayo clinic and Cockcroft formulae). $r=0.8328 p<0.0001, r=0.8175 p<0.0001, r=0.7104 p<0.0001$, respectively.
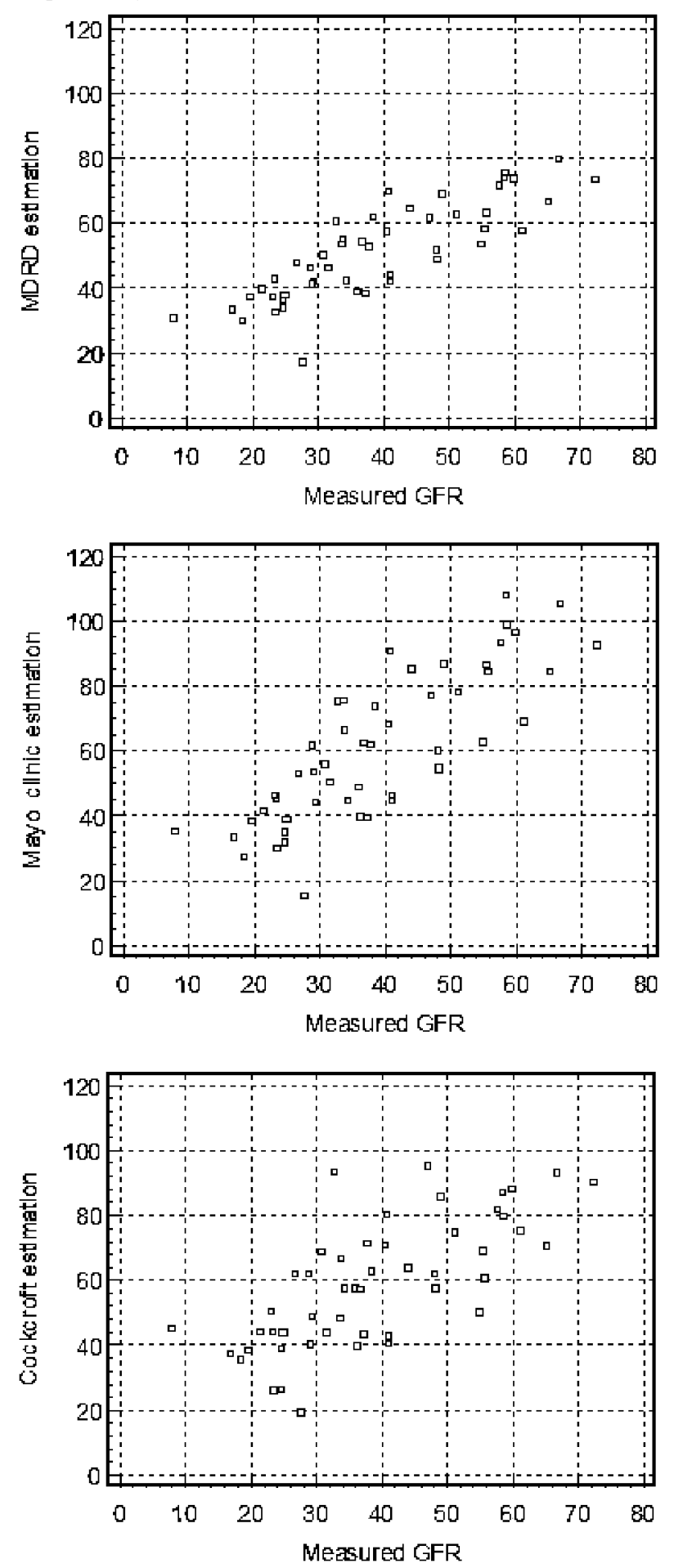
Fig. 2. Bland and Altman plots for measured and estimated GFR (MDRD, Mayo clinic and Cockcroft formulae). The continuous line represents the mean difference between measured and estimated GFR, whereas the dashed lines represent the limits of agreement (mean difference $\pm 2 S D$ ).
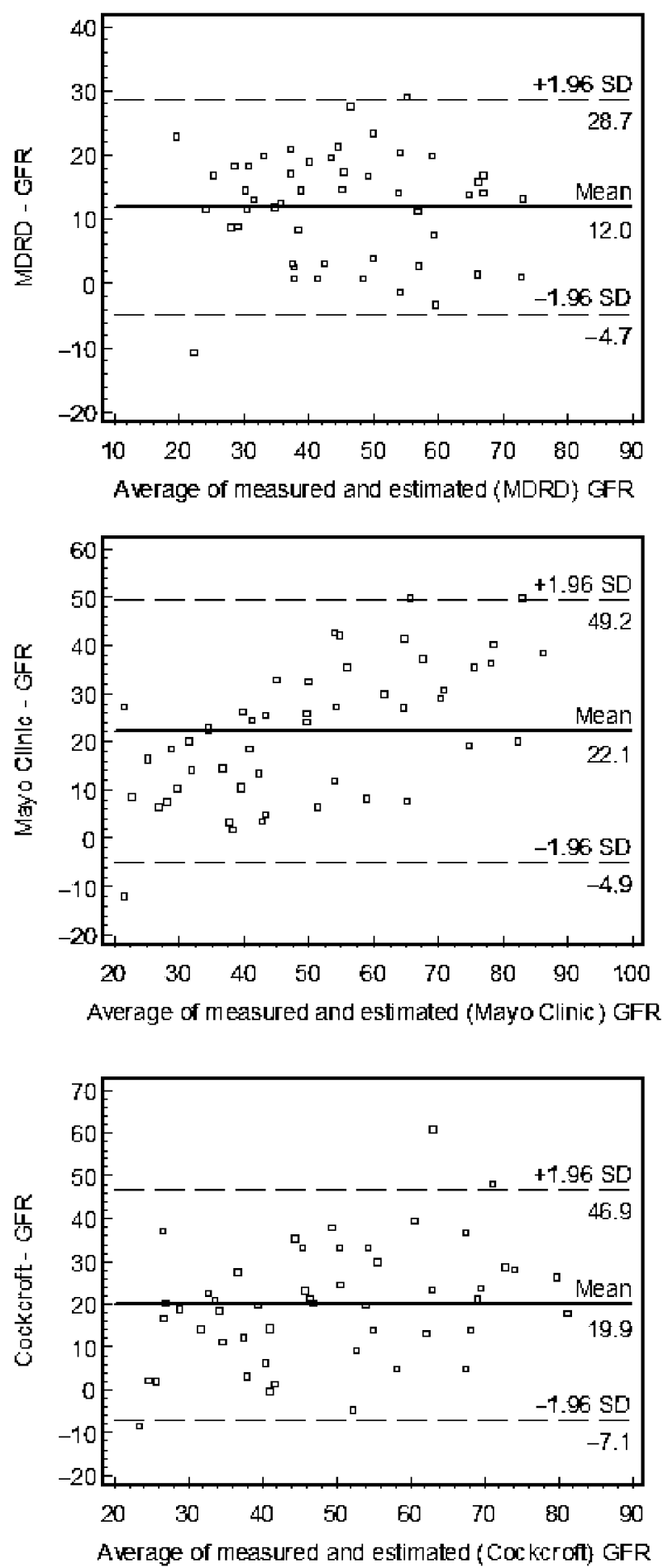

Numerous studies have demonstrated that creatinine-based formulae are more precise for estimating GFR than using serum creatinine (20). Moreover, formulae also offer the advantage of simplicity over classic reference methods for GFR measurement (inuline, ${ }^{51} \mathrm{Cr}$-EDTA, etc.). Many authors have then used the Cockcroft or MDRD formulae to study and follow GFR in heart transplant recipients $(5,8,11)$. Nevertheless, these formulae could be criticized. Moreover, they have not been strongly validated in this specific population of heart transplant recipients. Cantarovich et al. have shown good correlation between GFR and the Cockcroft formula (41). However, they only used regression analysis that was statistically insufficient to prove the formula's 
accuracy. The Bland and Altman analysis seems to be more appropriate in this type of analysis (38). To note, the mean measured GFR was lower in our population than in the one reported by Cantarovich et al. (39 \pm 15 and 71 $\pm 28 \mathrm{~mL} / \mathrm{min} / 1.73 \mathrm{~m}^{2}$ respectively). The Mayo Clinic formula has been little validated in other studies.

Our results (bias, limits of agreement and accuracy) are in favour of MDRD formula use as compared with the Cockcroft and Mayo Clinic formulae for the estimation of the GFR in heart transplant patients. One explanation could be found in the characteristics of the original studied populations for the determination of each formula. Cockcroft and Gault have developed their formula studying 248 patients without renal failure (24). Their reference method was creatinine clearance, which is well known to overestimate GFR (due to creatinine tubular secretion) (17). It is thus not surprising that numerous studies observed that the Cockcroft formula largely overestimates the GFR in a renal failure population $(20,25,42)$. This is particularly true in a CRF population because creatinine tubular secretion rises when GFR decreases $(16,17)$. We can confirm these results again in our population of heart transplant patients whose GFR function is mostly low. The population of the MDRD study was larger (1628 patients) and quite different. Levey et al. measured GFR with a reference technique (iothalamate clearance) in CRF patients (mean GFR $39.8 \mathrm{~mL} / \mathrm{min} / 1.73 \mathrm{~m}^{2}$ ) (25). In terms of GFR, our heart transplant patients were comparable to the MDRD population. This probably explains our better results using this formula for the GFR estimation in these heart transplant recipients. Nevertheless, the MDRD formula has also clear limitations, mainly in subjects with a normal GFR or normal serum creatinine levels. In this situation, the MDRD greatly underestimates the true GFR $(26,27,43-48)$. This fact is linked to a variation in creatinine in the serum calibration assay which has great consequences when creatinine values are low (49). The lack of accuracy of the MDRD formula can also be explained by the fact that the MDRD formula has been elaborated exclusively from a renal failure population and that the relationship between creatinine and GFR are not the same in normal and renal failure population $(27,46)$. For this reason, Rule et al. from the Mayo Clinic have proposed a new equation. They have elaborated this formula studying 580 healthy subjects (kidney donors) with a mean GFR of $101 \pm 17 \mathrm{~mL} / \mathrm{min} / 1.73 \mathrm{~m}^{2}$ and $320 \mathrm{CRF}$ patients whose mean GFR was $48 \pm 25 \mathrm{~mL} / \mathrm{min} / 1.73 \mathrm{~m}{ }^{2}$ (26). However, their sample appears too small and heterogeneous. Applied to our population, this equation overestimates the isotopic GFR as much as the Cockcroft formula does. This is in agreement with Froissart et al., who were the first to demonstrate that the Mayo Clinic equation overestimates the measured GFR in healthy populations or even in patients with a GFR ranging between 60 and $90 \mathrm{~mL} / \mathrm{min} / 1.73 \mathrm{~m}^{2}(50)$. The overestimation of GFR by the Mayo Clinic formula has been recently confirmed by Cirillo et al. and Bosma et al. in a population of renal transplant recipients $(30,31)$.

Up to now, the MDRD formula is thus certainly the best among the creatinine-based formulae to estimate the GFR in heart transplant patients with renal failure. The results of the MDRD formula must however be interpreted with circumspection. Indeed, systematic bias with the MDRD formula in our population has reached $+12 \mathrm{~mL} / \mathrm{min} / 1.73 \mathrm{~m}^{2}$. This overestimation should not be considered as negligible. Moreover, the accuracy of the formula has been relatively poor (57\% of the estimated GFR is over $30 \%$ measured GFR). These results are also quite different from those published about the accuracy of the MDRD formula in other CRF, non-transplant populations (absolute bias lower than $\left.5 \mathrm{~mL} / \mathrm{min} / 1.73 \mathrm{~m}^{2}\right)(28,51,52)$. On the other hand, our results are similar to those of the renal graft population, which were recently published. All these studies also describe the poor precision and accuracy of the MDRD formula (although better than that of the Cockcroft formula) in the estimation of the measured GFR $(29,30,39,40,53)$. Especially in renal transplant patients with renal failure, these authors describe a non-negligible overestimation of GFR (bias over $5 \mathrm{~mL} / \mathrm{min} / 1.73 \mathrm{~m}^{2}$ ) by the MDRD formula $(30,39,40,53)$. Moreover, Skluzacek et al. and Lamb et al. having analysed the MDRD formula bias in CRF liver transplant recipients and in elderly patients with CRF, have also described such an overestimation (bias of +18.7 and $+10 \mathrm{~mL} / \mathrm{min} / 1.73 \mathrm{~m}^{2}$, respectively) $(54,55)$. Rimon et al. confirmed Lamb's results with another methodology (56). We think that these different populations (an elderly population and renal, heart or liver transplant patients) share at least one common characteristic: the serum creat-inine concentration is largely influenced by muscle mass reduction (chronic disease, chronic therapy by corticoids, etc.) $(29,30,39,40)$. Regarding transplant populations, Tomlanovich et al. have also shown creatinine tubular hypersecretion, which seemed dependent on cyclosporine therapy (16). Serum creatinine is the principal variable in the MDRD equation. If the GFR is decreasing whereas the serum creatinine concentration is not rising as expected, because of muscle mass reduction or tubular hypersecretion, the MDRD formula results will be abnormally high. Such a hypothesis can also explain in part the overestimation noted with the Cockcroft and Mayo Clinic formulae.

There are, however, several limitations to our study. First, our sample is rather small and may not cover the entire GFR range in total heart transplant patients. We have, however, compared our GFR results with those published by Lindelöw et al. (2). This publication is of great importance because the authors measured the GFR $\left({ }^{51} \mathrm{Cr}\right.$-EDTA plasmatic clearance) precisely in a large population of heart transplant patients $(\mathrm{n}=151)$ with a long follow-up period. One year after heart grafting, the mean GFR in their patients was $52 \pm 19 \mathrm{~mL} / \mathrm{min} / 1.73$ $\mathrm{m}^{2}$. After nine yr however, the GFR had decreased to $37 \pm 17 \mathrm{~mL} / \mathrm{min} / 1.73 \mathrm{~m}^{2}$. Our results are comparable. Indeed, the mean GFR was $50 \pm 15 \mathrm{~mL} / \mathrm{min} / 1.73 \mathrm{~m}^{2}$ in patients with a follow-up period shorter than 12 months 
and $36 \pm 14 \mathrm{~mL} / \mathrm{min} / 1.73 \mathrm{~m}^{2}$ in those with a follow-up period of over 12 months. The GFR range in our population appears thus quite representative of the GFR range in a global heart transplant population. We also confirm the data proving that nearly all heart transplant recipients have CRF (GFR under $60 \mathrm{~mL} / \mathrm{min} / 1.73 \mathrm{~m}^{2}$ ) $(2,12)$. Our analysis is however limited to a Caucasian population. The conclusions of our study remain the same even if we limit statistical analysis to the 22 patients who had two GFR measurements (44 data) (data not shown). Moreover, the conclusions also remain similar when statistics are limited to the first 27 patients (data not shown).

Secondly, we used ${ }^{51} \mathrm{Cr}$-EDTA plasmatic clearance as the reference GFR measurement method, whereas in the MDRD and the Mayo Clinic studies, authors used iothalamate clearance (subcutaneous injection). Both methods are valid (57). Iothalamate has even some tubular secretion, contrary to ${ }^{51} \mathrm{Cr}$-EDTA, which is a strictly glomerular tracer (58). Like Froissart et al., we really think that our results cannot be due to the use of a different GFR measurement method (50).

Thirdly, one of the major problems with creat-inine-based formulae is the possible bias due to the difference in serum creatinine calibration assay. Serum creatinine values can vary by $0.3 \mathrm{mg} / \mathrm{dL}$ according to these differences in calibration (49). Each laboratory should in theory correct the MDRD formula according to its calibration and then validate it, but it is practically impossible. Moreover, biases in the formula due to different calibrations are especially relevant in subjects with a normal GFR and low serum creatinine. This problem is thus largely attenuated in a chronic kidney disease population (GFR60 mL/min/ $1.73 \mathrm{~m}^{2}$ ) such as our specific population $(49,59)$. At least, Wuyts et al. demonstrated that the MDRD formula was valid when using the rate-blanked compensated creatinine Jaffé method (Roche) as creatinine measurement method (60). One could eventually argue that other formulae have been published to estimate GFR and could have been tested in our population (20). The Nankivell formula may be especially of interest because it has been developed for renal graft transplant patients (61). However, this formula has not been validated and several authors have also illustrated the overestimation of GFR induced by this formula even in transplant populations $(29,30,39,62)$. We also confirm this overestimation in our heart transplant patients. Indeed, statistical results are the worst with the Nankivell formula $\left(r=0.6861\right.$, bias of $+28.1 \mathrm{~mL} / \mathrm{min} / 1.73 \mathrm{~m}^{2}$, limits of agreement of +2 to $\left.54 \mathrm{~mL} / \mathrm{min} / 1.73 \mathrm{~m}^{2}\right)$.

\section{Conclusion}

It has been shown that the MDRD formula was significantly better than Cockcroft and the Mayo Clinic formulae for GFR estimation in heart transplant recipient populations. However, the MDRD formula accuracy is far from perfect. Our results in heart transplant patients are similar to those described in renal transplant patients. If a precise GFR is needed in clinical practice or in epidemiological or interventional studies, we do recommend the use of a reference method measurement like inulin, ${ }^{51} \mathrm{Cr}$-EDTA, iohexol, or iothalamate techniques. The same recommendations have also been made for renal transplantation $(39,62)$. We do suggest measuring GFR with such a reference method at least once or twice a year in heart transplant patients.

\section{Acknowledgements}

We want to thank Ms Rosalie Bonmariage and Claire Wilcock for their help in the redaction of the manuscript. This work is dedicated to the memory of Dr Jean-Claude Demoulin who devoted a large part of his medical career to caring for heart transplant patients.

\section{References}

1. HeRlitZ H, Lindelow B. Renal failure following cardiac transplantation. Nephrol Dial Transplant 2000: 15: 311.

2. Lindelow B, Bergh CH, Herlitz H, WAagstein F. Predictors and evolution of renal function during 9 yr following heart transplantation. J Am Soc Nephrol 2000: 11: 951.

3. Myers BD, Ross J, Newton L, Luetscher J, Perlroth M. Cyclosporine-associated chronic nephropathy. N Engl J Med 1984: 311 : 699.

4. WILKINSON AH, COHEN DJ. Renal failure in the recipients of nonrenal solid organ transplants. J Am Soc Nephrol 1999: 10: 1136.

5. OJo AO, HELD PJ, PORT FK et al. Chronic renal failure after transplantation of a nonrenal organ. N Engl J Med 2003: $349: 931$.

6. HANSEN JM, Hoy CE, STRANDGAARD S. Fish oil and cy-closporin A-induced renal hypoperfusion in kidney-transplanted patients. Nephrol Dial Transplant 1995: 10: 1745.

7. Bakker RC, Van Kooten C, Van De Lagemaat-PaApe ME, Daha MR, Paul LC. Renal tubular epithelial cell death and cyclosporin A. Nephrol Dial Transplant 2002: 17: 1181.

8. Veillon S, Caillard S, Epailly E, Eisenmann B, Hannedouche T, Moulin B. Chronic renal failure after cardiac transplantation: predictive factors and influence on mortality-results of a monocenter study in 141 patients. Transplant Proc 2002: 34: 2819.

9. Shiba N, Chan MC, Kwok BW, Valantine HA, Rob-Bins RC, Hunt SA. Analysis of survivors more than $10 \mathrm{yr}$ after heart transplantation in the cyclosporine era: Stanford experience. J Heart Lung Transplant 2004: 23: 155. 
Published in: Clinical Transplantation (2006), vol. 20, iss. 5, Sep-Oct, pp. 596-603.

Status: Postprint (Author's version)

10. Satchithananda DK, Parameshwar J, Sharples L et al. The incidence of end-stage renal failure in 17 years of heart transplantation: a single center experience. J Heart Lung Transplant 2002: 21: 651.

11. Rubel JR, MiLford EL, MCKAY DB, JARCHO JA. Renal insufficiency and end-stage renal disease in the heart transplant population. J Heart Lung Transplant 2004: 23: 289.

12. GReEnberg A, ThOmpson ME, GrifFith BJ et al. Cyclosporine nephrotoxicity in cardiac allograft patients -a seven-year follow-up. Transplantation 1990: 50: 589.

13. TinAwi M, MiLler L, BASTANi B. Renal function in cardiac transplant recipients: retrospective analysis of 133 consecutive patients in a single center. Clin Transplant 1997: 11: 1.

14. Zietse R, Balk AH, vd Dorpel MA, Meeter K, Bos E, Weimar W. Time course of the decline in renal function in cyclosporinetreated heart transplant recipients. Am J Nephrol 1994: 14: 1.

15. LEWIS RM, VAN BUREN CT, RADOVANCEVIC B et al. Impact of long-term cyclosporine immunosuppressive therapy on native kidneys versus renal allografts: serial renal function in heart and kidney transplant recipients. J Heart Lung Transplant 1991: 10: 63.

16. Tomlanovich S, Golbetz H, Perlroth M, Stinson E, Myers BD. Limitations of creatinine in quantifying the severity of cyclosporine-induced chronic nephropathy. Am J Kidney Dis 1986: 8: 332.

17. Perrone RD, Madias NE, Levey AS. Serum creatinine as an index of renal function: new insights into old concepts. Clin Chem 1992: 38: 1933.

18. Goral S, YNARES C, SHYR Y, YeOH TK, JohnSON HK. Long-term renal function in heart transplant recipients receiving cyclosporine therapy. J Heart Lung Transplant 1997: 16: 1106.

19. WALSER M. Assessing renal function from creatinine measurements in adults with chronic renal failure. Am J Kidney Dis 1998: 32: 23.

20. K/DOQI guidelines. K/DOQI clinical practice guidelines for chronic kidney disease: evaluation, classification, and stratification. Am J Kidney Dis 2002: 39: S1.

21. Gonwa TA, Mai ML, Pilcher J et al. Stability of long-term renal function in heart transplant patients treated with induction therapy and low-dose cyclosporine. J Heart Lung Transplant 1992: 11: 926.

22. Kunst H, ThOMPSON D, HodsOn M. Hypertension as a marker for later development of end-stage renal failure after lung and heartlung transplantation: a cohort study. J Heart Lung Transplant 2004: 23: 1182.

23. Ostermann ME, Rogers CA, SAEEd I, Nelson SR, Murday AJ. Pre-existing renal failure doubles 30-day mortality after heart transplantation. J Heart Lung Transplant 2004: 23: 1231.

24. CocKCROFT DW, GAULT MH. Prediction of creatinine clearance from serum creatinine. Nephron 1976: 16: 31.

25. LeVey AS, Bosch JP, Lewis JB, Greene T, Rogers N, Roth D. A more accurate method to estimate glomerular filtration rate from serum creatinine: a new prediction equation. Modification of Diet in Renal Disease Study Group. Ann Intern Med 1999: $130: 461$.

26. Rule AD, Larson TS, Bergstralh EJ, SLeZAK JM, JACOBSEn SJ, Cosio FG. Using serum creatinine to estimate glomerular filtration rate: accuracy in good health and in chronic kidney disease. Ann Intern Med 2004: 141: 929.

27. Froissart M, Rossert J, Jacquot C, PaIllard M, HouilliER P. Predictive performance of the modification of diet in renal disease and cockcroft-gault equations for estimating renal function. J Am Soc Nephrol 2005: 16: 763.

28. Pierrat A, Gravier E, Saunders C et al. Predicting GFR in children and adults: a comparison of the Cock-croft-Gault, Schwartz, and modification of diet in renal disease formulas. Kidney Int 2003: 64: 1425.

29. RAJU DL, GROVER VK, SHOKER A. Limitations of glomerular filtration rate equations in the renal transplant patient. Clin Transplant 2005: 19: 259

30. Bosma RJ, Doorenbos CR, Stegeman CA, VAn Der Heide JJ, NAVIS G. Predictive performance of renal function equations in renal transplant recipients: an analysis of patient factors in bias. Am J Transplant 2005: 5: 2193.

31. Cirillo M, Anastasio P, De Santo NG. Relationship of gender, age, and body mass index to errors in predicted kidney function. Nephrol Dial Transplant 2005: 20: 1791.

32. Chantler C, Garnett ES, Parsons V, Veall N. Glomerular filtration rate measurement in man by the single injection methods using 51Cr-EDTA. Clin Sci 1969: 37: 169.

33. BRochNER-MORTENSEN J, RodBRo P. Optimum time of blood sampling for determination of glomerular filtration rate by singleinjection [51Cr]EDTA plasma clearance. Scand J Clin Lab Invest 1976: 36: 795.

34. Du Bois D, Du BoIs E. A formula to estimate the approximative surface area if height and weight be known. Arch Intern Med 1916: 17: 863.

35. MAZZACHi BC, PEAKE MJ, EhrhaRdt V. Reference range and method comparison studies for enzymatic and Jaffe creatinine assays in plasma and serum and early morning urine. Clin Lab 2000: 46: 53.

36. LEVEY AS, GREENE T, KUSEK J, BECK GJ, GROUP MS. A simplified equation to predict glomerular filtration rate from serum creatinine. J Am Soc Nephrol 2000: 11: A0828.

37. DELANAYE P, RADERMECKER RP, RORIVE M, DEPAS G, KRZESINSKI JM. Indexing glomerular filtration rate for body surface area in obese patients is misleading: concept and example. Nephrol Dial Transplant 2005: 20: 2024

38. BLAND JM, ALTMAN DG. Statistical methods for assessing agreement between two methods of clinical measurement. Lancet 1986: 1: 307. 
Published in: Clinical Transplantation (2006), vol. 20, iss. 5, Sep-Oct, pp. 596-603.

Status: Postprint (Author's version)

39. GASPARI F, FERRARI S, STUCCHI N et al. Performance of different prediction equations for estimating renal function in kidney transplantation. Am J Transplant 2004: 4: 1826.

40. Mariat C, Alamartine E, AfIANi A et al. Predicting glomerular filtration rate in kidney transplantation: are the K/DOQI guidelines applicable? Am J Transplant 2005: 5: 2698.

41. Cantarovich M, Giannetti N, Cecere R. Correlation between serum creatinine, creatinine clearance, the calculated creatinine clearance and the glomerular filtration rate in heart transplant patients. J Heart Lung Transplant 2002: 21: 815.

42. Spinler SA, Nawarskas JJ, Boyce EG, Connors JE, Charland SL, Goldfarb S. Predictive performance of ten equations for estimating creatinine clearance in cardiac patients. Iohexol Cooperative Study Group. Ann Phar-macother 1998: 32: 1275.

43. Bertolatus JA, GodDARD L. Evaluation of renal function in potential living kidney donors. Transplantation 2001: 71: 256.

44. Bostom AG, Kronenberg F, Ritz E. Predictive performance of renal function equations for patients with chronic kidney disease and normal serum creatinine levels. J Am Soc Nephrol 2002: 13: 2140.

45. Hoste EA, DAmen J, VAnHolder RC et al. Assessment of renal function in recently admitted critically ill patients with normal serum creatinine. Nephrol Dial Transplant 2005: 20: 147.

46. Ibrahim H, Mondress M, Tello A, Fan Y, Koopmein-ers J, Thomas W. An alternative formula to the Cock-croft-Gault and the modification of diet in renal diseases formulas in predicting GFR in individuals with Type 1 diabetes. J Am Soc Nephrol 2005: 16: 1051.

47. Lin J, KNight EL, Hogan ML, Singh AK. A comparison of prediction equations for estimating glomerular filtration

rate in adults without kidney disease. J Am Soc Nephrol 2003: 14: 2573.

48. Vervoort G, Willems HL, WetZels JF. Assessment of glomerular filtration rate in healthy subjects and normo-albuminuric diabetic patients: validity of a new (MDRD) prediction equation. Nephrol Dial Transplant 2002: 17: 1909.

49. CORESh J, AStor BC, MCQUillan G et al. Calibration and random variation of the serum creatinine assay as critical elements of using equations to estimate glomerular filtration rate. Am J Kidney Dis 2002: 39: 920.

50. Froissart M. Assessment of the predictive performances of the 'Mayo Clinic' equations. Ann Intern Med 2005: 142: 673.

51. Lewis J, AgOdoA L, CHEeK D et al. Comparison of cross-sectional renal function measurements in African Americans with hypertensive nephrosclerosis and of primary formulas to estimate glomerular filtration rate. Am J Kidney Dis 2001: $38: 744$.

52. Poggio ED, Wang X, Greene T, Van Lente F, Hall PM. Performance of the modification of diet in renal disease and CockcroftGault equations in the estimation of GFR in health and in chronic kidney disease. J Am Soc Nephrol 2005: 16: 459.

53. Poge U, Gerhardt T, Palmedo H, Klehr HU, Sau-erbruch T, Woitas RP. MDRD equations for estimation of GFR in renal transplant recipients. Am J Transplant 2005: 5: 1306.

54. Lamb EJ, WebB MC, Simpson DE, CoAKLEy AJ, Newman DJ, O'RiORDAN SE. Estimation of glomerular filtration rate in older patients with chronic renal insufficiency: is the modification of diet in renal disease formula an improvement? J Am Geriatr Soc 2003: 51: 1012 .

55. SkluZacek PA, SzewC RG, Nolan CR III, Riley DJ, Lee S, Pergola PE. Prediction of GFR in liver transplant candidates. Am J Kidney Dis 2003: 42: 1169

56. Rimon E, KAGANSKy N, Cojocaru L, Gindin J, SCHATTNER A, LEVY S. Can creatinine clearance be accurately predicted by formulae in octogenarian in-patients? QJM 2004: 97: 281.

57. Brandstrom E, Grzegorczyk A, Jacobsson L, Friberg P, Lindahl A, Aurell M. GFR measurement with iohexol and 51CrEDTA. A comparison of the two favoured GFR markers in Europe. Nephrol Dial Transplant 1998: 13: 1176.

58. OdLIND B, HALLGREN R, SOHTELl M, LindSTROM B. Is 125 I iothalamate an ideal marker for glomerular filtration? Kidney Int 1985: 27: 9 .

59. Murthy K, SteVens LA, StARK PC, LeVey AS. Variation in the serum creatinine assay calibration: a practical application to glomerular filtration rate estimation. Kidney Int 2005: 68: 1884.

60. WUYTS B, BERNARD D, VAN DEN NN et al. Re-evaluation of formulas for predicting creatinine clearance in adults and children, using compensated creatinine methods. Clin Chem 2003: 49: 1011.

61. NANKiVell BJ, GRuenewald SM, Allen RD, Chapman JR. Predicting glomerular filtration rate after kidney transplantation. Transplantation 1995: 59: 1683

62. Mariat C, Alamartine E, Barthelemy JC et al. Assessing renal graft function in clinical trials: can tests predicting glomerular filtration rate substitute for a reference method? Kidney Int 2004: 65: 289. 